\title{
Lower cathelicidin concentrations in Irish athletes compared to controls: a role for vitamin $\mathrm{D}$ ?
}

\author{
J.J. Todd ${ }^{1}$, E.M. McSorley ${ }^{1}$, L.K. Pourshahidi ${ }^{1}$, S.M. Madigan ${ }^{2}$, E. Laird ${ }^{3}$, R.R. Weir ${ }^{1}$, \\ M. Healy ${ }^{4}$, M.B.E. Livingstone ${ }^{1}$, C. Beggan ${ }^{1}$, L. Beggan ${ }^{1}$ and P.J. Magee \\ ${ }^{1}$ Northern Ireland Centre for Food and Health, Ulster University, Coleraine, BT52 1SA, \\ ${ }^{2}$ Irish Institute of Sport, Sports Campus Ireland, Abbotstown, Dublin, Republic of Ireland, \\ ${ }^{3}$ School of Medicine, Trinity College Dublin, Republic of Ireland and \\ ${ }^{4}$ Department of Biochemistry, St. James' Hospital, Dublin, Republic of Ireland
}

Despite strong in vitro evidence supporting pleiotropic actions of vitamin D in the immune system ${ }^{(1)}$, including synthesis of LL-37 antimicrobial peptide ${ }^{(2)}$, human studies have yielded inconsistent results. LL-37 has been linked with total 25-hydroxyvitamin D $[25(\mathrm{OH}) \mathrm{D}]$ concentrations and the number of self-reported upper respiratory tract infection symptoms in endurance athletes ${ }^{(3)}$. This observational study investigated whether LL-37 concentration varied between athletes and a general population control group and also tested if total $25(\mathrm{OH}) \mathrm{D}$ was a positive predictor of LL-37 concentration.

Overall, 221 stored plasma samples from male and female athletes $(n 101)$ and a healthy control group $(n$ 120) were obtained from four previous studies and analysed for LL-37 using an ELISA. Total 25(OH)D concentration was quantified by LC-MS/MS during each original study. Prior to statistical analyses, outliers $(n=24)$ were removed.

\begin{tabular}{|c|c|c|c|c|}
\hline \multirow[b]{2}{*}{ Measure } & \multicolumn{2}{|c|}{ Athletes (n 96) } & \multicolumn{2}{|c|}{$\begin{array}{l}\text { Healthy controls } \\
(n 101)\end{array}$} \\
\hline & Mean & SD & Mean & SD \\
\hline Age, years & $21^{\mathrm{a}}$ & 3 & 24 & 5 \\
\hline Height, $\mathrm{cm}$ & $170^{\mathrm{b}}$ & 10 & 173 & 9 \\
\hline Weight, kg & $67 \cdot 50^{\mathrm{a}}$ & 12.59 & $75 \cdot 17$ & $13 \cdot 21$ \\
\hline $\mathrm{BMI}, \mathrm{kg} / \mathrm{m}^{2}$ & $23 \cdot 27^{\mathrm{a}}$ & $2 \cdot 57$ & $25 \cdot 16$ & $4 \cdot 38$ \\
\hline Total $25(\mathrm{OH}) \mathrm{D}, \mathrm{nmol} / \mathrm{L}$ & $59 \cdot 26^{\mathrm{a}}$ & $30 \cdot 11$ & $35 \cdot 87$ & 18.93 \\
\hline PTH, $\mathrm{pg} / \mathrm{mL}$ & $39 \cdot 24$ & $17 \cdot 10$ & $41 \cdot 37$ & $18 \cdot 19$ \\
\hline $\mathrm{LL}-37, \mathrm{ng} / \mathrm{mL}$ & $29.93^{\mathrm{b}}$ & $18 \cdot 89$ & $43 \cdot 76$ & $26 \cdot 63$ \\
\hline
\end{tabular}

Athletes had a significantly lower mean LL-37 concentration than controls. In contrast, the athlete group exhibited a higher mean total $25(\mathrm{OH}) \mathrm{D}$ concentration compared to the control group. Total $25(\mathrm{OH}) \mathrm{D}$ concentration did not predict LL-37 concentration overall $(\beta=0.073, P=0.386)$, or in either group after adjusting for age, sex, BMI and season of sampling (athletes $\beta=-0.033$, $P=0.762$; controls $\beta=0.145, P=0.197$ ). These findings question the purported link between vitamin $\mathrm{D}$ and LL-37 in vivo. Although significantly lower LL-37 concentrations were observed in athletes compared to controls, the clinical implications of this disparity require further investigation.

This study was funded by the Department of Employment and Learning, Northern Ireland and Translational Research Group: Diabetes, Endocrinology \& Nutrition, HSC Research \& Development Division, Public Health Agency, Belfast. Ethical approval was obtained from the University of Ulster Research Ethics Committee (REC/08/0044; REC/13/0235; REC/14/0087) or from the Office of Research Ethics Committees Northern Ireland (13/NI/0091) and the study was conducted according to the guidelines laid down in the Declaration of Helsinki.

1. Baeke F, Etten EV, Overbergh L et al. (2007) Nutr Res Rev 20, 106-118.

2. Vandamme D, Landuyt B, Luyten W et al. (2012) Cell Immunol 280, 22-35.

3. He C, Handzlik M, Fraser WD et al. (2013) Exerc Immunol Rev 19, 86-101. 